\title{
Microphonics and Active Compensation
}

Joshua Einstein-Curtis

LLRF Workshop 2017, Barcelona, Spain

19 October 2017 


\section{Acknowledgements}

- Cryogenics: Ben Hansen, Renzhuo Wang, Michael White

- Tuner and ARC Group: Jeremiah Holzbauer, Yuriy Pischalnikov, Warren Schappert

- Cavity and CM Design: Joshua Kaluzny, Tom Petersen

- LLRF: Brian Chase, Larry Doolittle, Carlos Serrano, LCLS-II Collaboration, et al.

- Project Operations: Elvin Harms

- JLab: Tom Powers 


\section{Outline}

- Introduction

- Definition (Microphonics/LFD)

- Effects

- Facility

- Diagnosis

- Mitigation

- Passive

- Active

- Auxiliary Systems Considerations 


\section{Introduction}

- Superconducting cavities have extremely high Q values, which leads to minor physical variations able to cause singificant RF differences

- On higher frequency cavities, such as the $3.9 \mathrm{GHz}$ cavities used for LCLSII, displacement becomes a significant issue as $0.1 \mathrm{~mm}$ movement can lead to fundamental mode frequency shifts on the order of $1 \mathrm{kHz} / \mathrm{um}$ 


\section{Definition}

- Lorentz Force Detuning

- RF Gradient

- Microphonics

- Pressure Fluctuations

- Cryogenics

- Mechanical Distortions

- Cryogenics

- Vacuum Equipment

- HVAC

- Water

- Unknown Unknowns (Larry)

- Cable variations 
- Dynamic vs Static; Pulsed vs CW

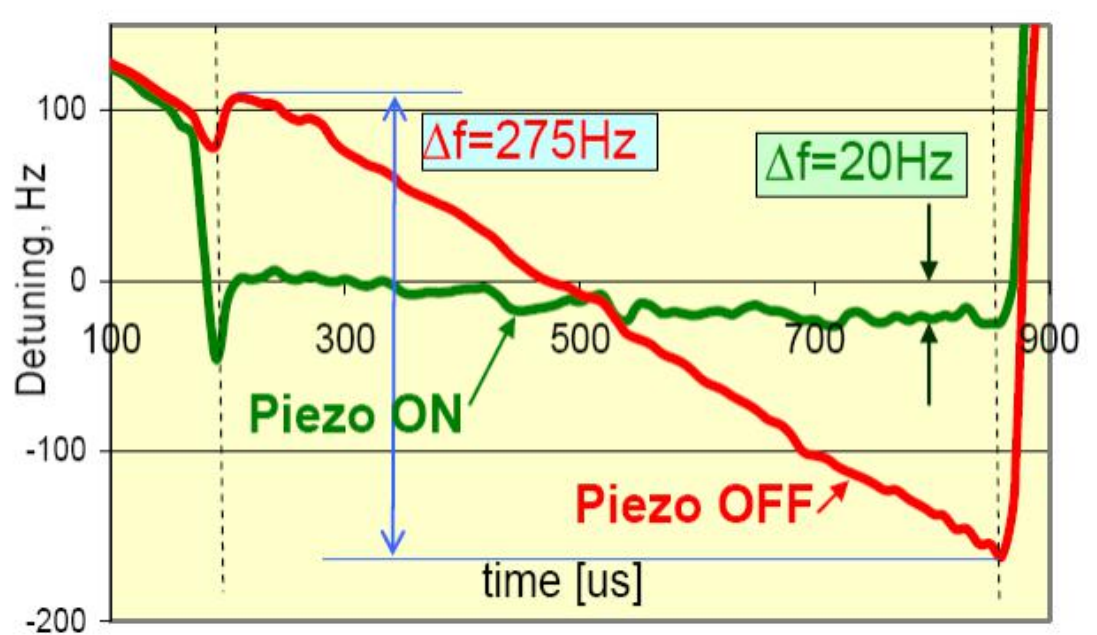

Figure 7: CCII average Lorentz force detuning at $\mathrm{EAcc}=26 \mathrm{MV} / \mathrm{m}$ with and without compensation

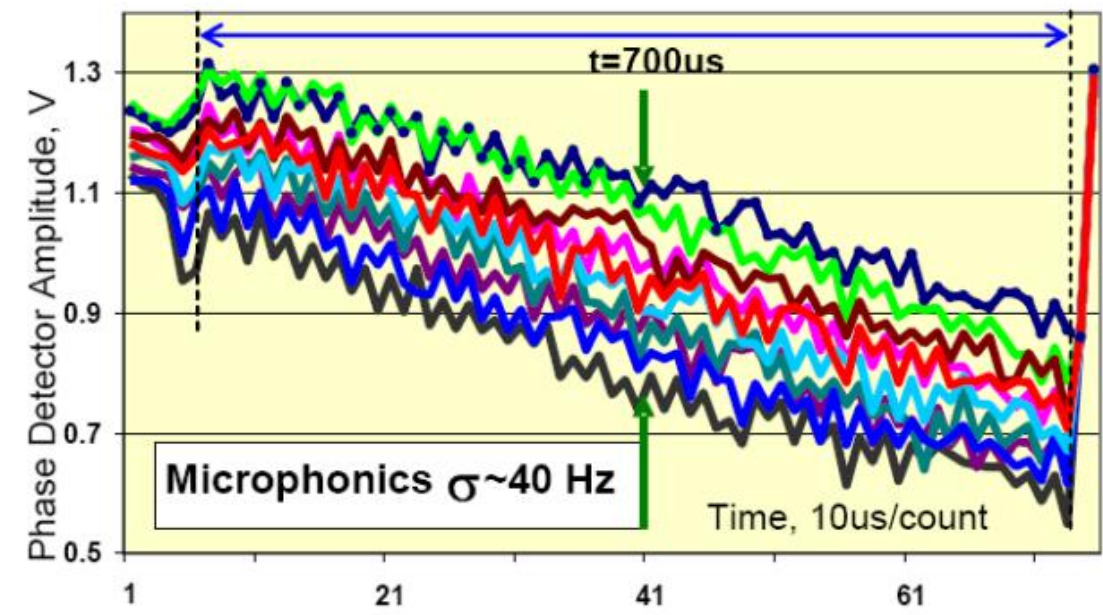

Figure 9: Pulse-to-pulse variations in the CCII phase detector signal due to microphonics. 


\section{The Math}

- The steady state amplitude and phase controls needed for microphonics is given by:

$$
\begin{gathered}
P_{R F}=\frac{(\beta+1) L}{4 \beta Q_{F P C}(r / Q)}\left\{\left(E+I_{0} Q_{F P C}(r / Q) \cos \varphi_{B}\right)^{2}+\left(2 Q_{L} \frac{\delta f}{f_{0}} E+I_{0} Q_{F P C}(r / Q) \sin \varphi_{B}\right)^{2}\right\} \\
\varphi_{R F}=\operatorname{arcTan}\left(\frac{2 Q_{L} \frac{\delta f}{f_{0}} E+I_{0} Q_{F P C}(r / Q) \sin \varphi_{B}}{E+I_{0} Q_{F P C}(r / Q) \cos \varphi_{B}}\right)
\end{gathered}
$$

- One interesting outcome of the math is that beam loading reduces the control requirements due to microphonics.

*Frequently folks use the loaded- $Q, Q_{L}$ in place of the fundamental power coupler-Q, $Q_{F P C}$. 


\section{Other Labs}

- US Labs have started holding Microphonics Workshops, with the first held in 2015

- https://indico.fnal.gov/event/10555/

- Microphonics is not a single-lab problem 
Comparison of a Hardened (SL24) and Zone With No Improvements (SL25) During Truck Drive By

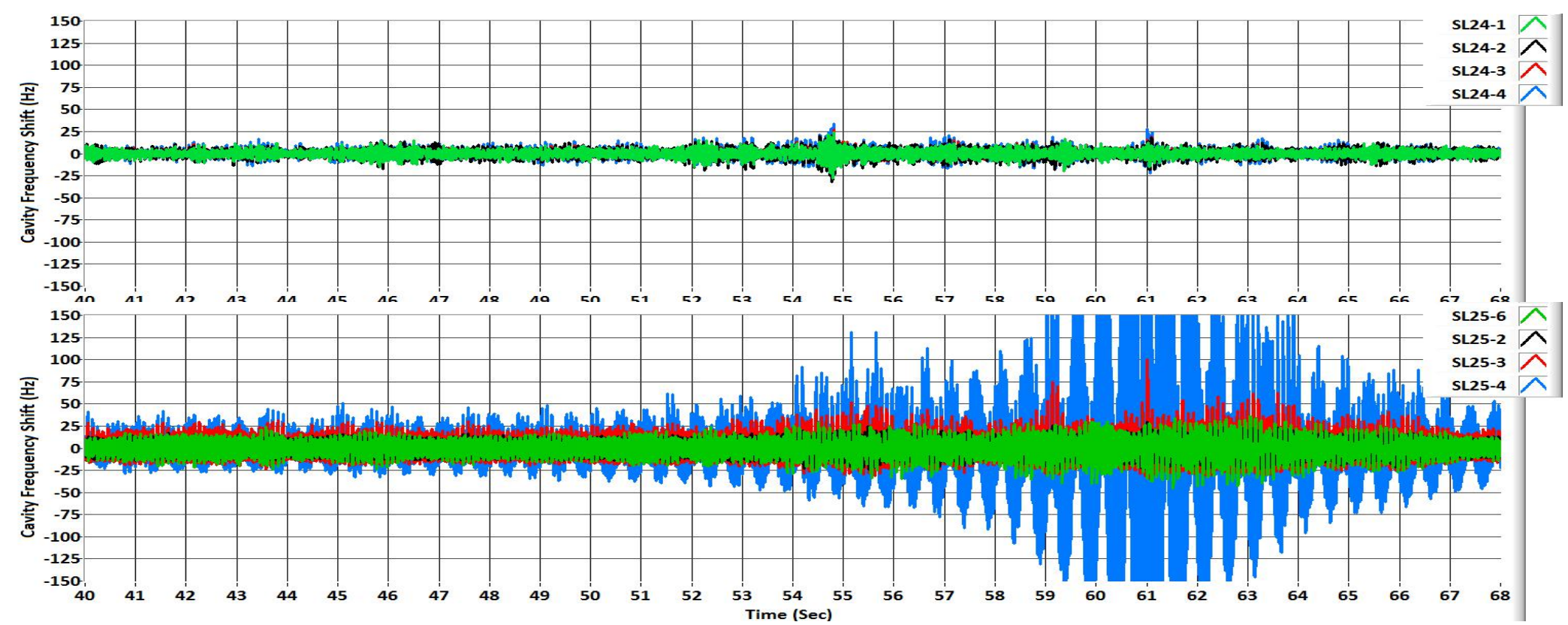

- A liquid nitrogen truck drove down the south linac service road at about $15 \mathrm{mph}$ passing the zone at time equals about 60 seconds.

- Cavities operated in GDR mode at $3 \mathrm{MV} / \mathrm{m}$ in order to avoid trips. 


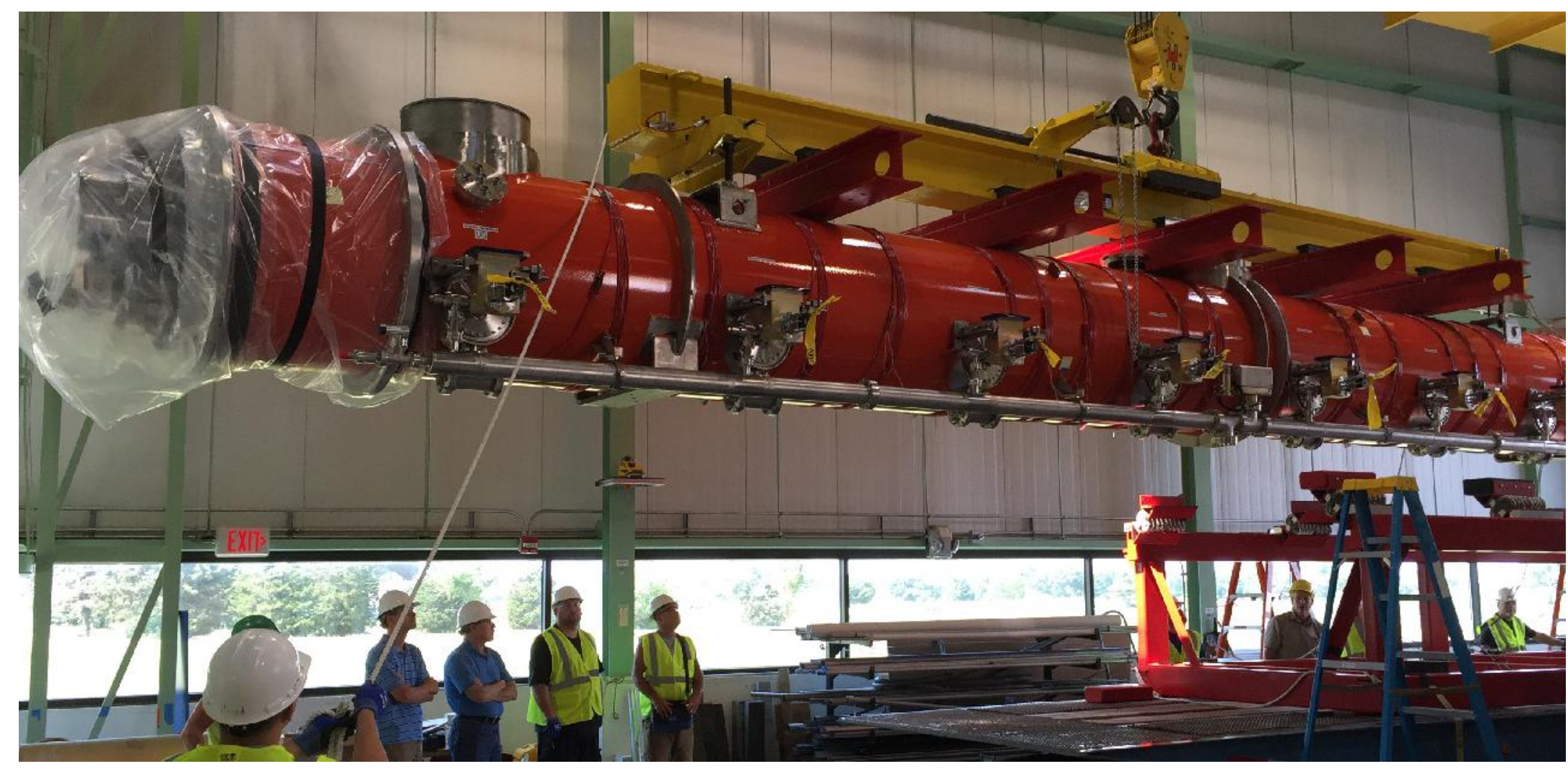




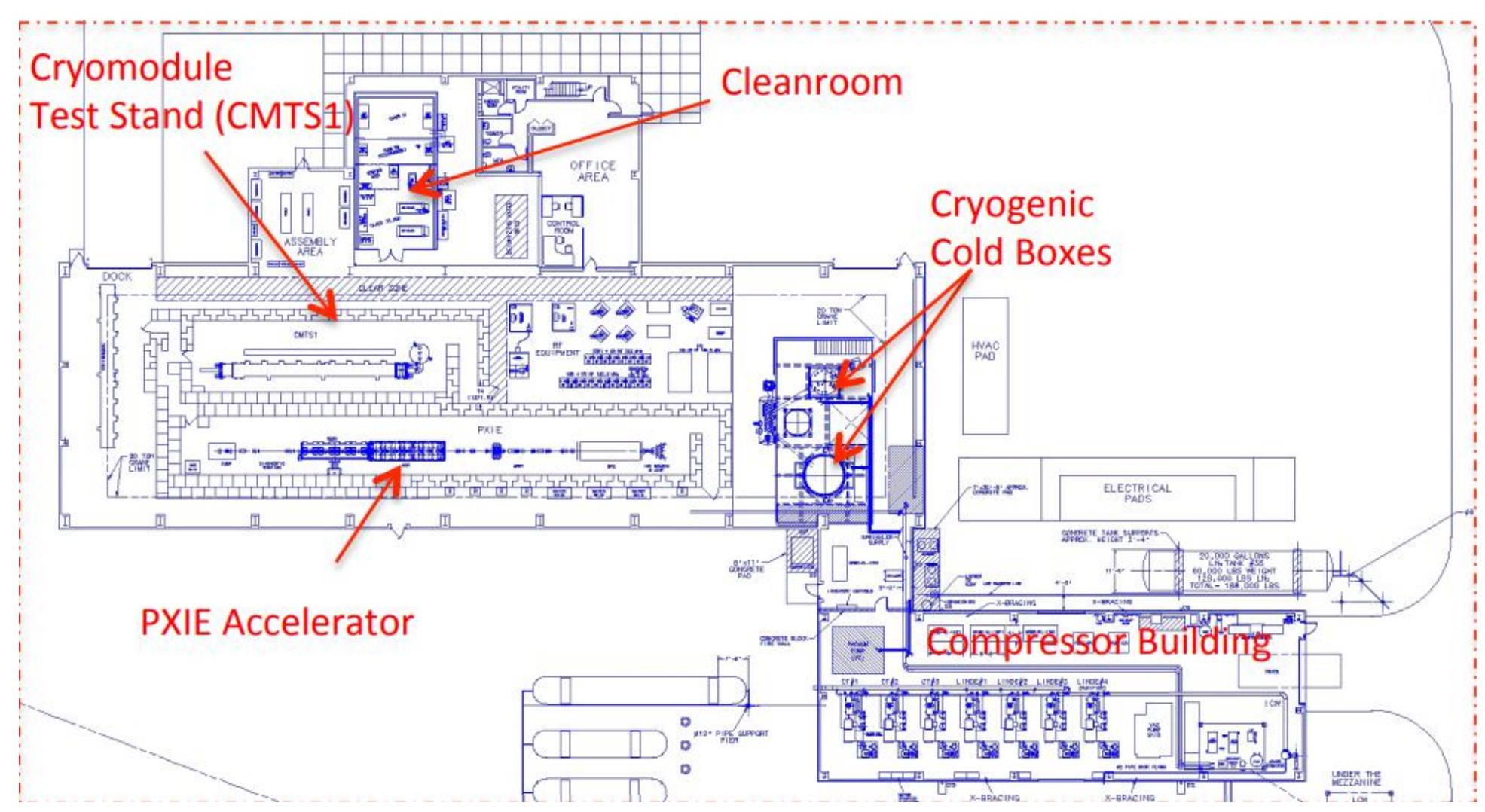


Initial Findings - F1.3-01

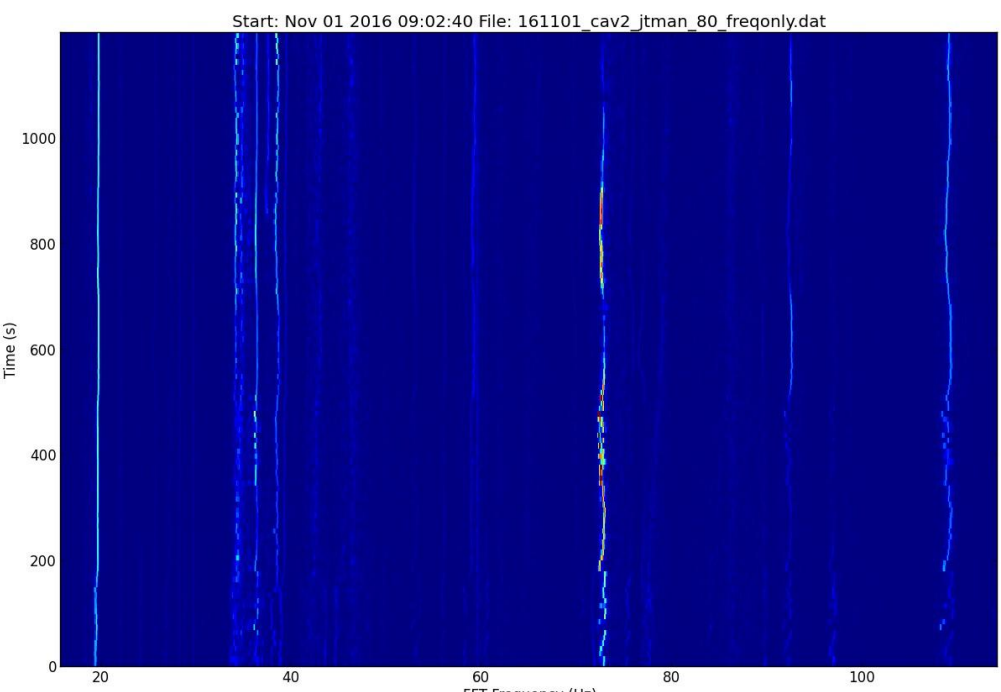

JT Valve at $60 \%$ open

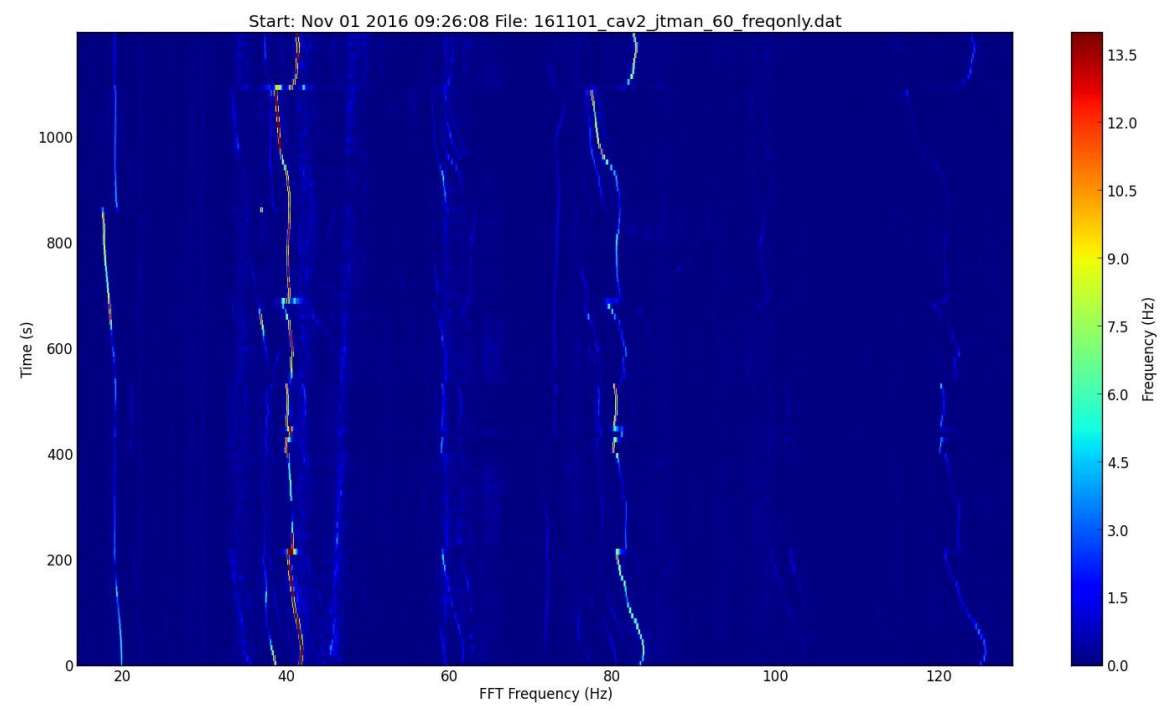

JT Valve at $80 \%$ open 

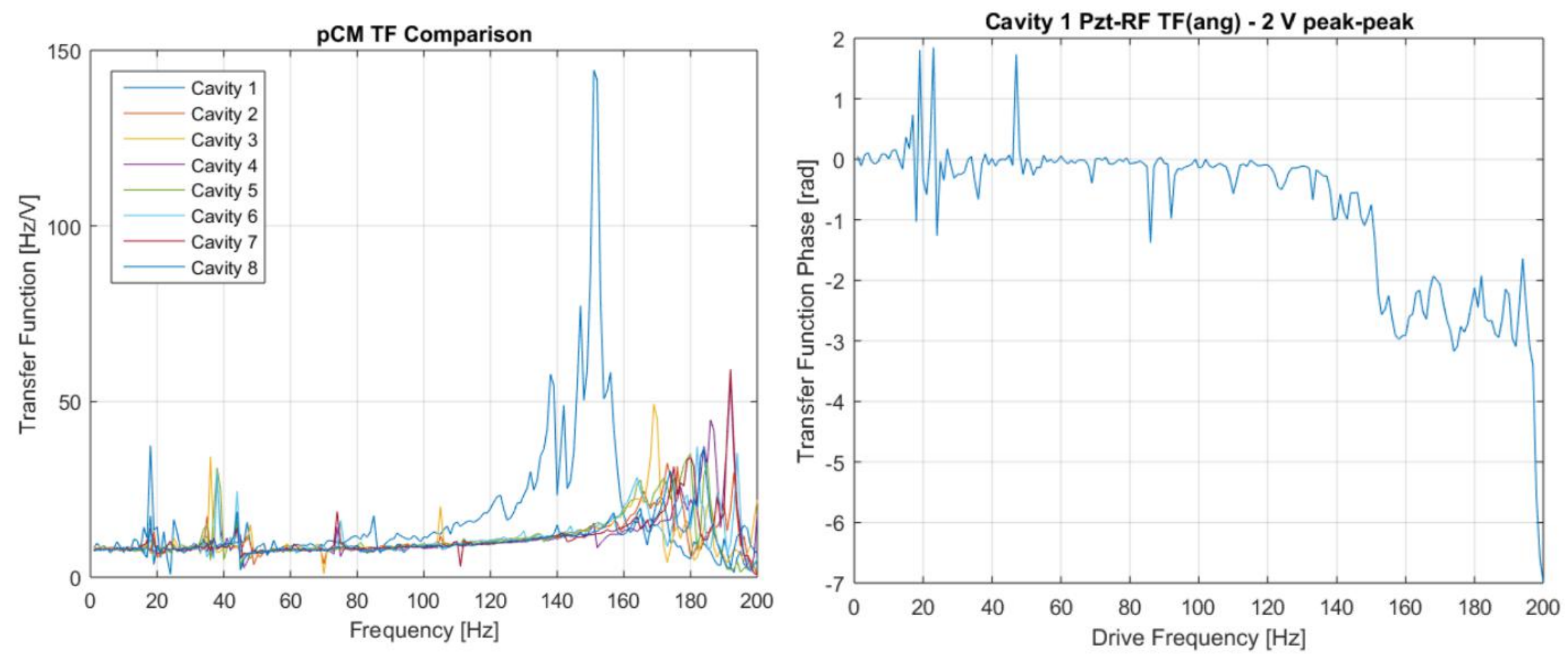
- Comparing performance of the standard cryogenics configuration, the microphonics environment in the F1.3-02 is a factor of $\sim 10$ improved

- Significant improvements in stability of the system, leading to a far more predictable detuning environment
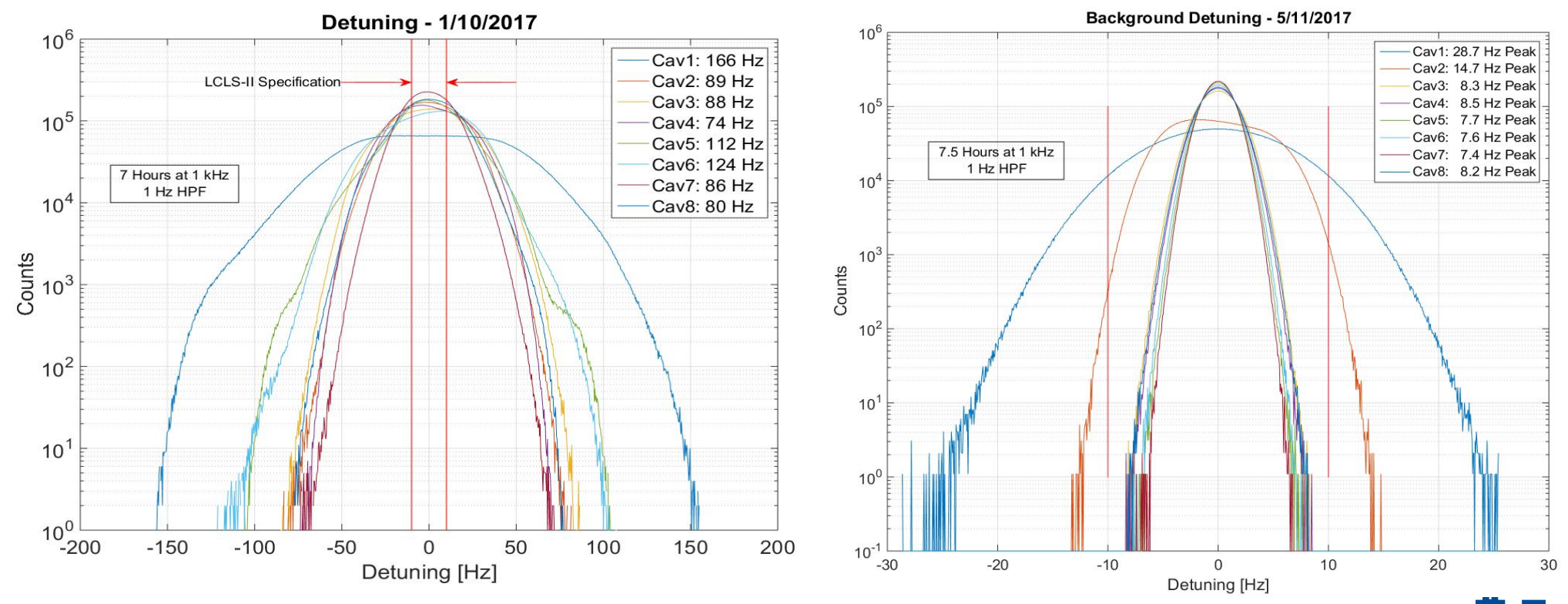
- Injection method

- The two-phase pipe was modified to include a baffle to avoid wind any damming effects or wind dragging due to the injection

- Cryomodule tilt due to tunnel installation

- Teststands include a tilt to mimic actual installation. Theories on gas and liquid Helium flow abound

- Cool-down line and piping

- Dead-head on cool-down line with osciallations in attached temperature sensors. Secondary effect, or primary problem?

- External sources

- Vacuum pumps? Facility water? Waveguide transmission?

- TAOs

- Rott developed theory in 1969 (see TAO part 1)

- Requires careful design of system 


\section{Determination}

- Considerations of the type of noise sources is necessary. Narrow-band vs broadband have different algorithms for efficient cancellation

- Stability analysis

- Understanding of system frequency-domain response over time and bandwidth of signals

- Cross-correlation analysis and spectral density analysis with windowing can provide further details

- Plotting statistical variance 
A Closer Look
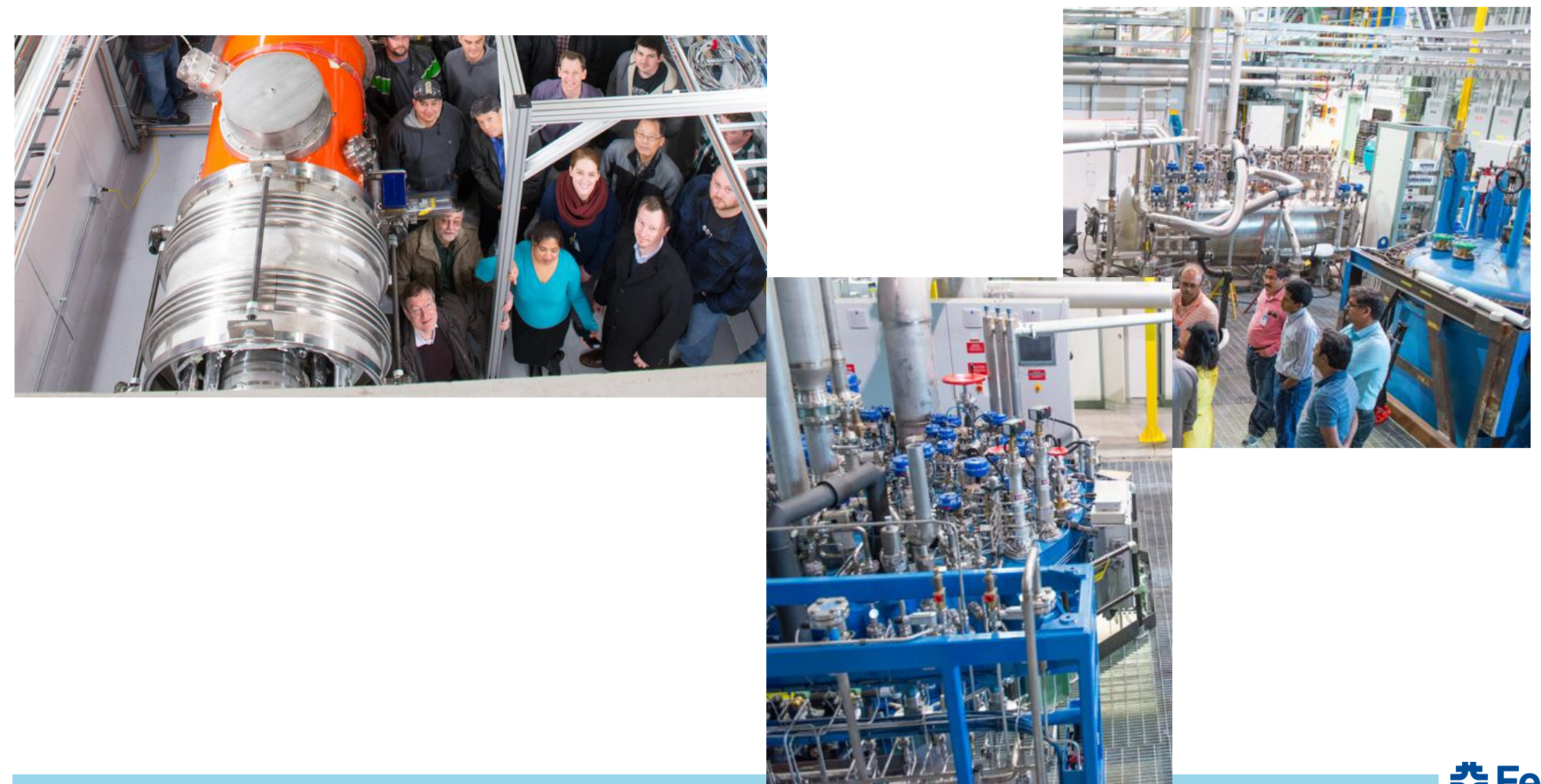

\# Fermilab 
- Broadband, calibrated source

- Simultaneous capture with sensors

- Modal Testing on warm structures

- Cavity-to-cavity coupling is readily tested

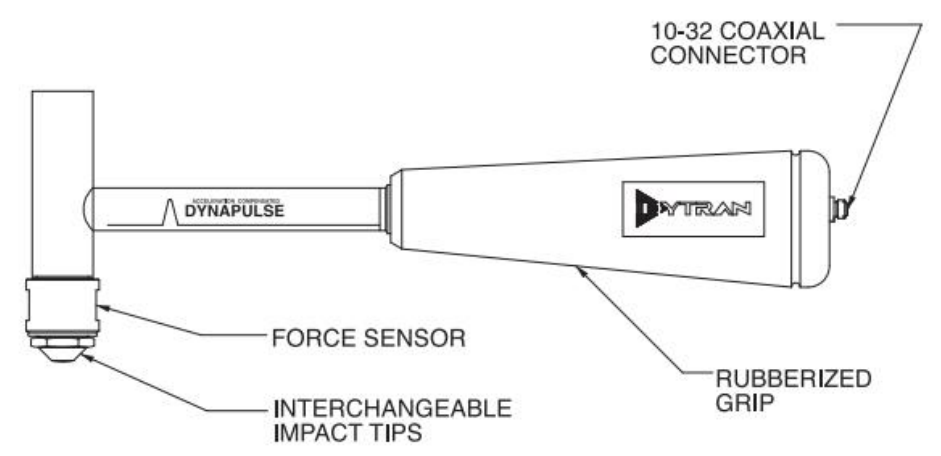

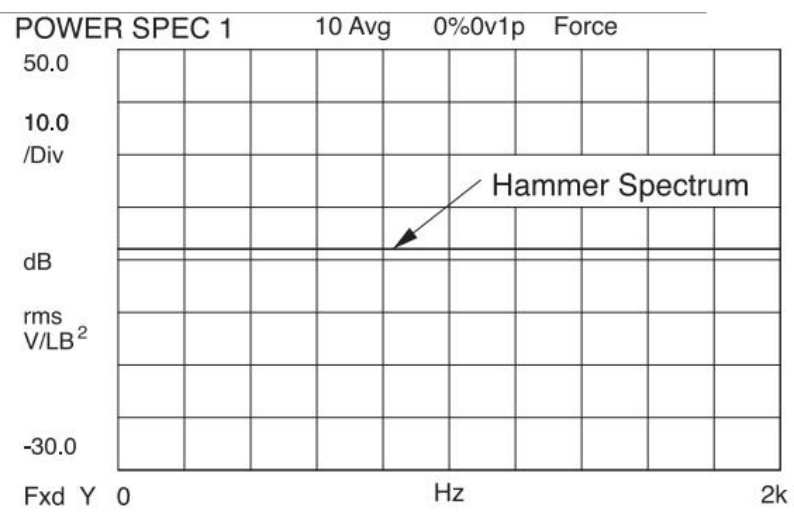

Figure 2: Impulse Spectrum, Aluminum Tip, No Extender

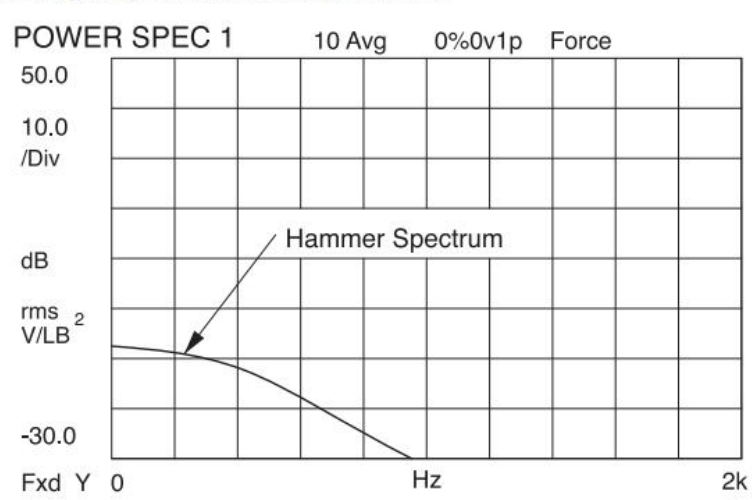

Figure 4: Impulse Spectrum, Soft Plastic Tip, One Head Extender 
- Initially is was unknown that TAOs were the culprit

- Several cryogenic variables were varied during long data captures to find correlations.

- Discovered that at Subcritical Supply Pressures the microphonics improved by factor of 10 !

- In addition: reduction in steady-state flow rate from $4.7 \mathrm{~g} / \mathrm{s}$ to $1.75 \mathrm{~g} / \mathrm{s}$, supply pressure stabilized, valve ice melted

- This coincident combination of improvements suggests TAOs in the valves were the main contributor to the high microphonics levels and $2 \mathrm{~K}$ Static Heat Load
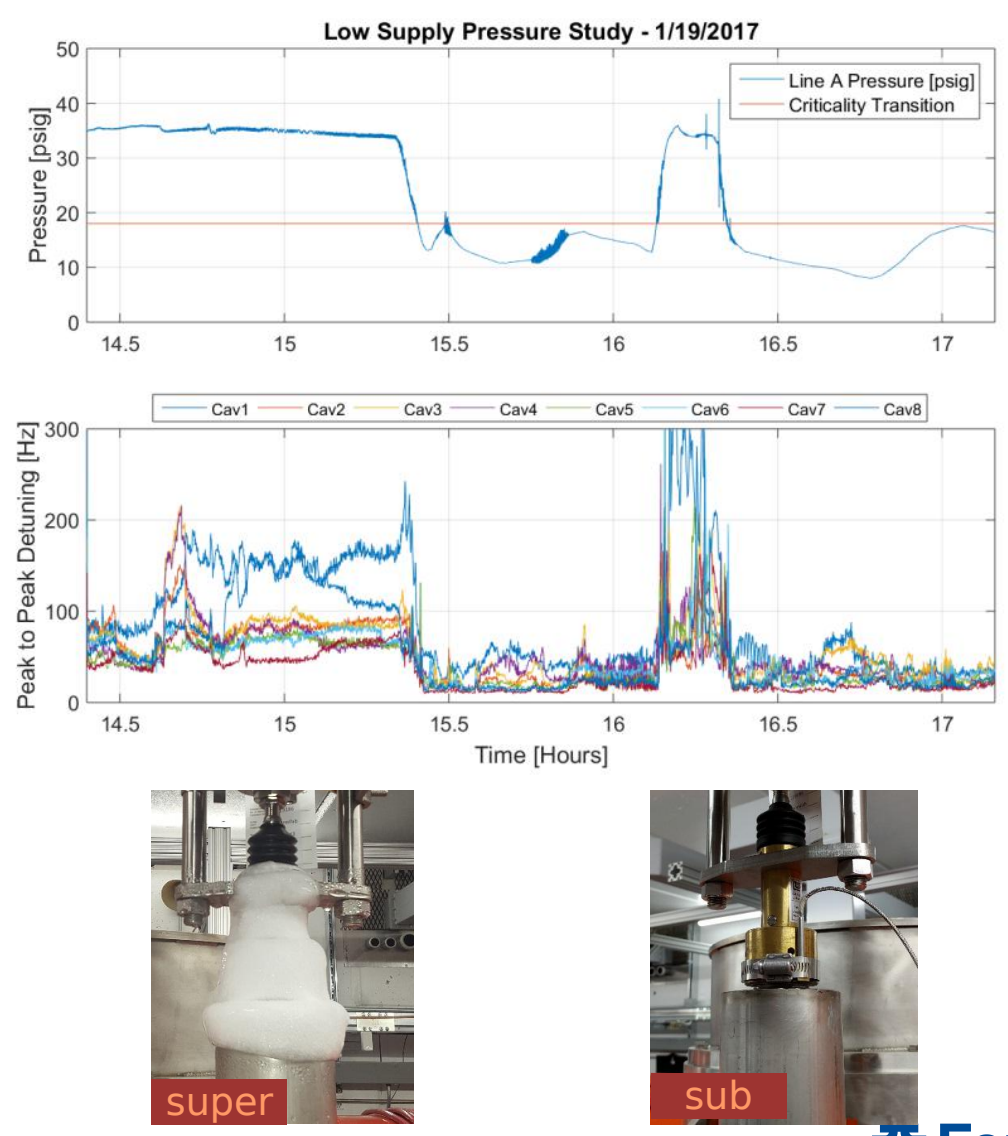
A: Full

Total Deformation - Mode

Type: Total Deformation

Frequency: $38.531 \mathrm{~Hz}$

$\square_{2.3852 \mathrm{Max}}^{2.302}$

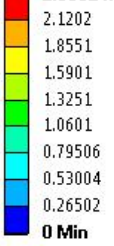

Mode No. Freq $(\mathrm{Hz})$

1. 8.5949

2. 8.9183

3. $\quad 11.622$

4. 29.559

5. $\quad 33.823$

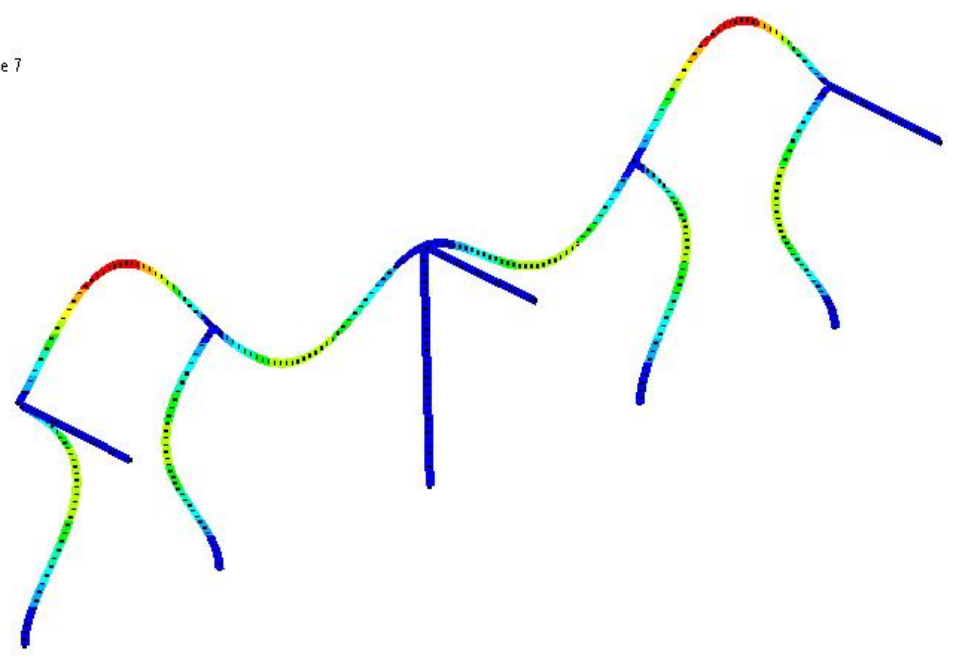

D: Full mod

formation - Mode 1

Type: Total Deformation
Frequency: $56.52 \mathrm{~Hz}$

Unit: in

$1.38 \operatorname{Max}$
1.2267
10733
0.92

$\begin{array}{rl}- & 1.0733 \\ - & 0.92 \\ 0.76666 & 0.6533\end{array}$

0.76666
0.61333

0.61333
0.46

0.40667
0.15333

$\mathbf{0}_{\mathbf{M} \text { in }}^{0}$

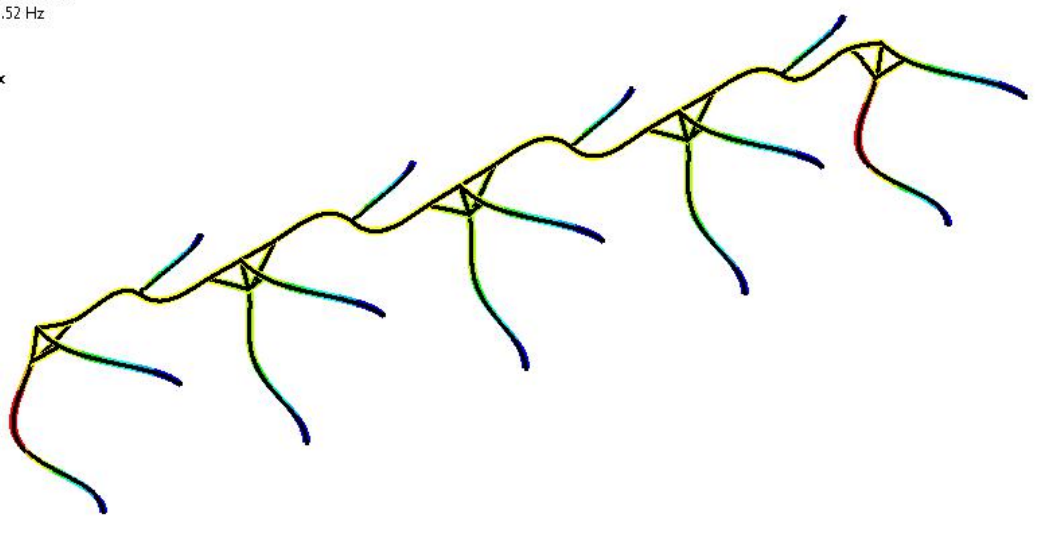

Mode No. Freq $(\mathrm{Hz})$

1. $\quad 56.52$

2. $\quad 57.769$

3. $\quad 57.81$

4. $\quad 57.829$

5. $\quad 58.226$ 


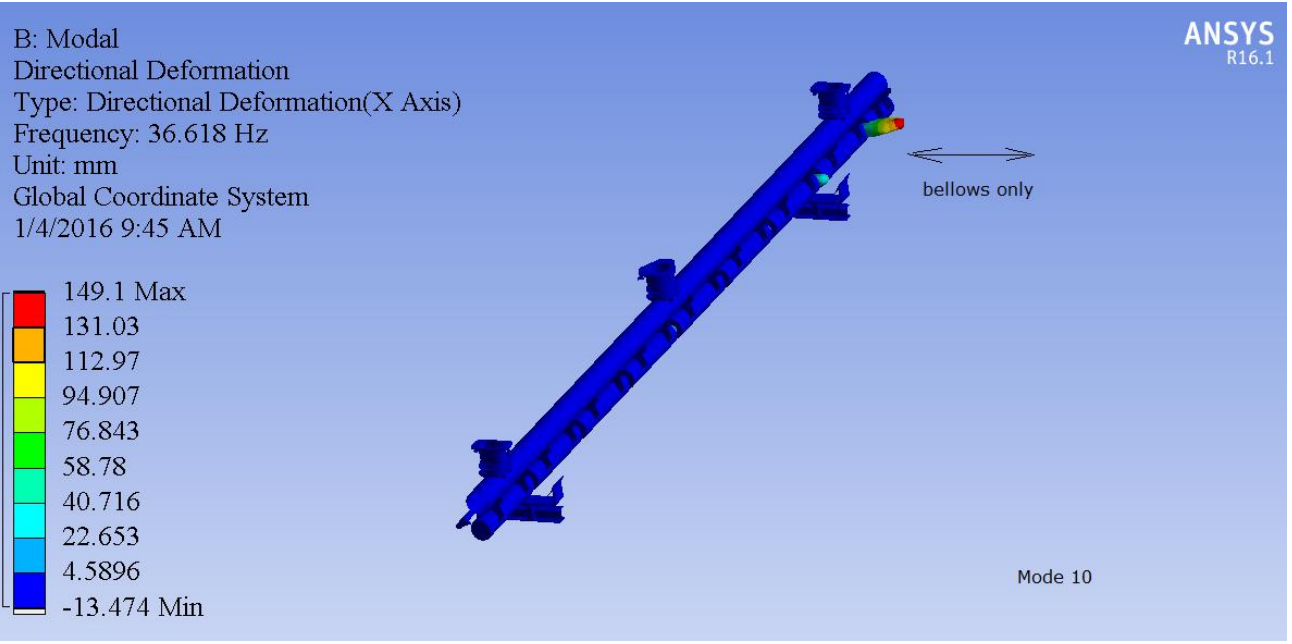

\begin{tabular}{|c|c|}
\hline Mode & Frequency $(\mathrm{Hz})$ \\
\hline 1 & 7.5612 \\
\hline 2 & 17.759 \\
\hline 3 & 20.540 \\
\hline 4 & 22.055 \\
\hline 5 & 25.182 \\
\hline 6 & 26.733 \\
\hline 7 & 27.641 \\
\hline 8 & 31.911 \\
\hline 9 & 33.422 \\
\hline 10 & 36.618 \\
\hline
\end{tabular}




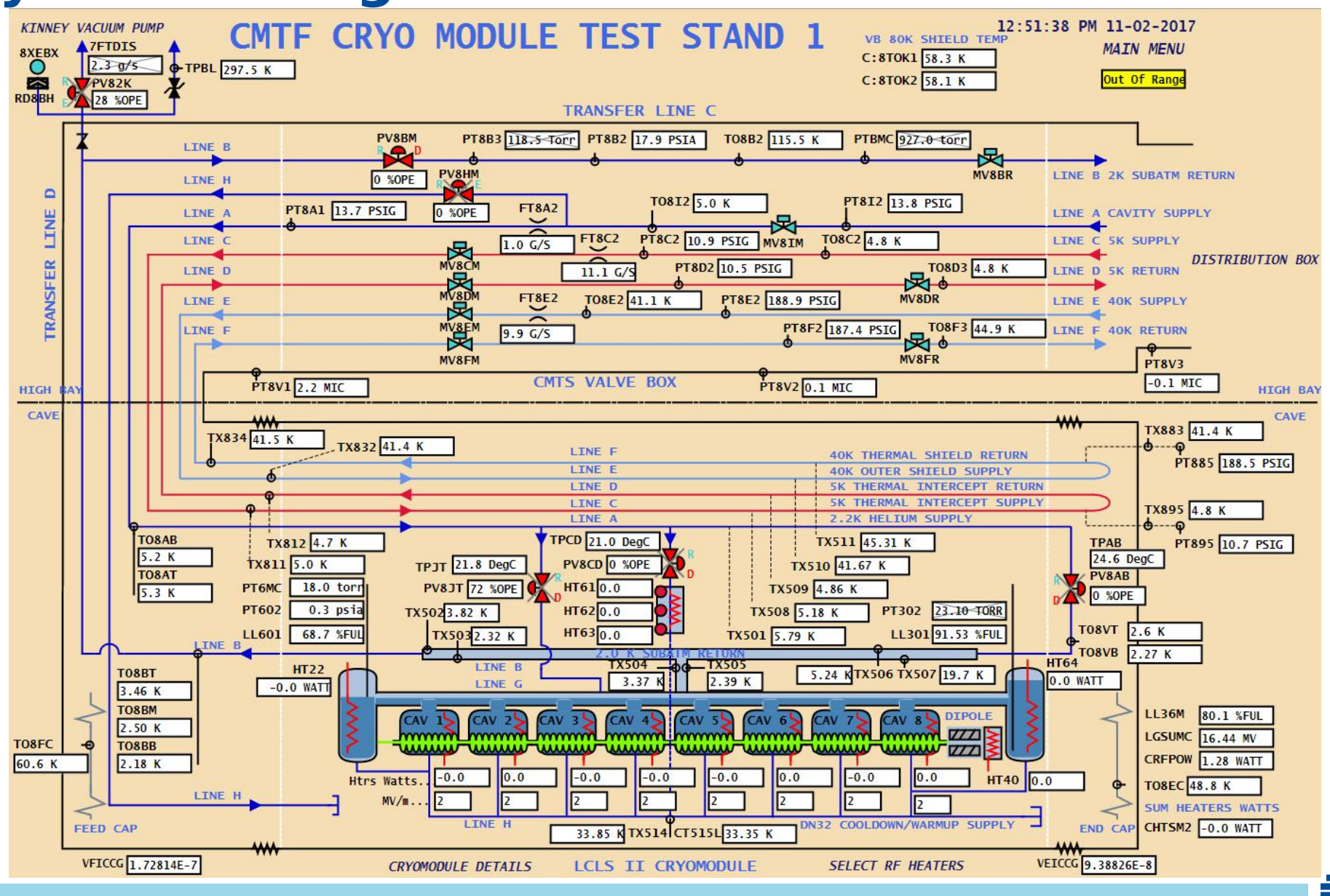




\section{Diagnosis}

- Fast pressure sensors

- Long-term data captures; Note FFT resolution

- RF power measurements

- Bubbles

- Cell Phones

- Microphones

- Geophones 


\section{Mitigation}

- What is active compensation?

- Is passive compensation and good design a form of active compensation? 


\section{Algorithms}

- Least Mean Square (LMS)

- Kalman Filtering

- 'Analog' Filter Bank

- Direct feedback

- Anything else?

- Active Cancellation

- Pulse-to-pulse correction

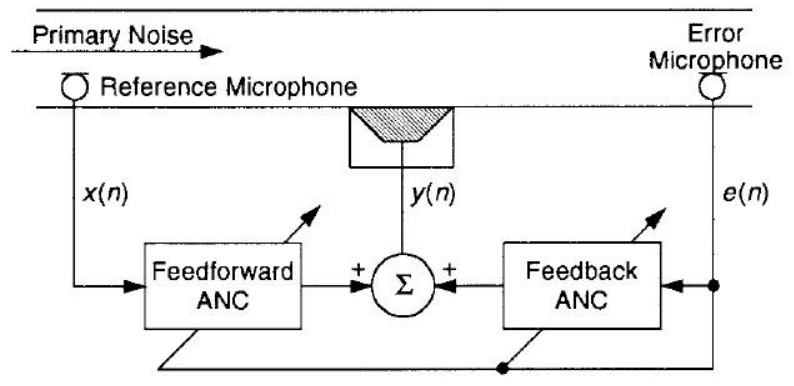

Fig. 17. Hybrid ANC system with combination of feedback ANC and feedforward ANC.

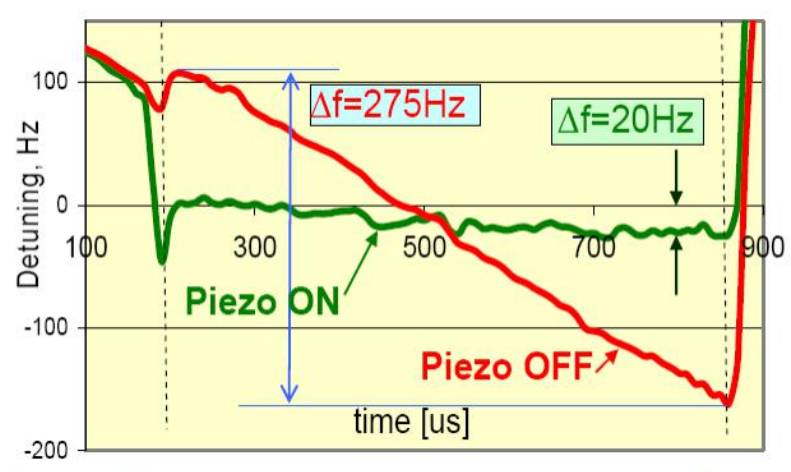

Figure 7: CCII average Lorentz force detuning at $\mathrm{EAcc}=26 \mathrm{MV} / \mathrm{m}$ with and without compensation 


\section{Mitigation}

- LMS, NXLMS, FNLMS

- Definition of basis function very important

- Some functions have feedback inherent in the structure

- Model-based controllers

- Currently available anywhere?

- A model is necessary regardless of whether this is dynamic to have a base design to compare to

- Full simulation of mechanical design

- Tuner, piping and support equipment can all contriubte to expected microphonics and LFD

- A mix of narrowband and broadband suppression techniques are likely desired, with characterization of all sources a necessity. 


\section{Detuning Filter Bank - Feed Forward Controller}

Discrete-time State Space Realization

- General form for a system whose

- Outputs and internal states depend linearly on the inputs and internal states

$\mathrm{u}$ is the detuning

$y$ is the piezo drive signal $x$ are estimates of the amplitudes of the cavity mechanical modes

- A can be decomposed into a $2 \times 2$ block diagonal matrix

- Ideal for implementation in an FPGA firmware

$$
\begin{array}{ccccccc}
x_{k+1} & = & \mathbf{A} & x_{k} & + & \mathbf{B} & u_{k} \\
y_{k+1} & = & \mathbf{C} & x_{k+1} & + & \mathbf{D} & u_{k}
\end{array}
$$

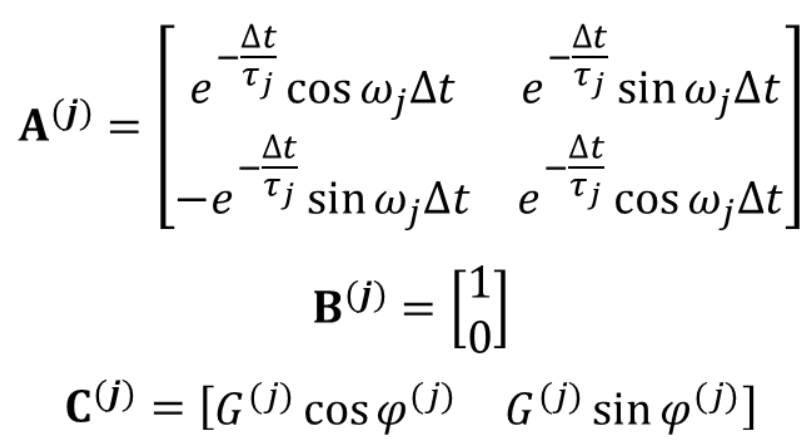




\section{Manual Compensation in CM2/Cavity 2}

- Detuning fed to a bank of parallel $2^{\text {nd }}$ order IIR filters

- Filter coefficients (frequency, bandwidth, gain, phase) are programmable

- Manually tuned filter coefficients can suppress cavity detuning by a factor of 3 or more

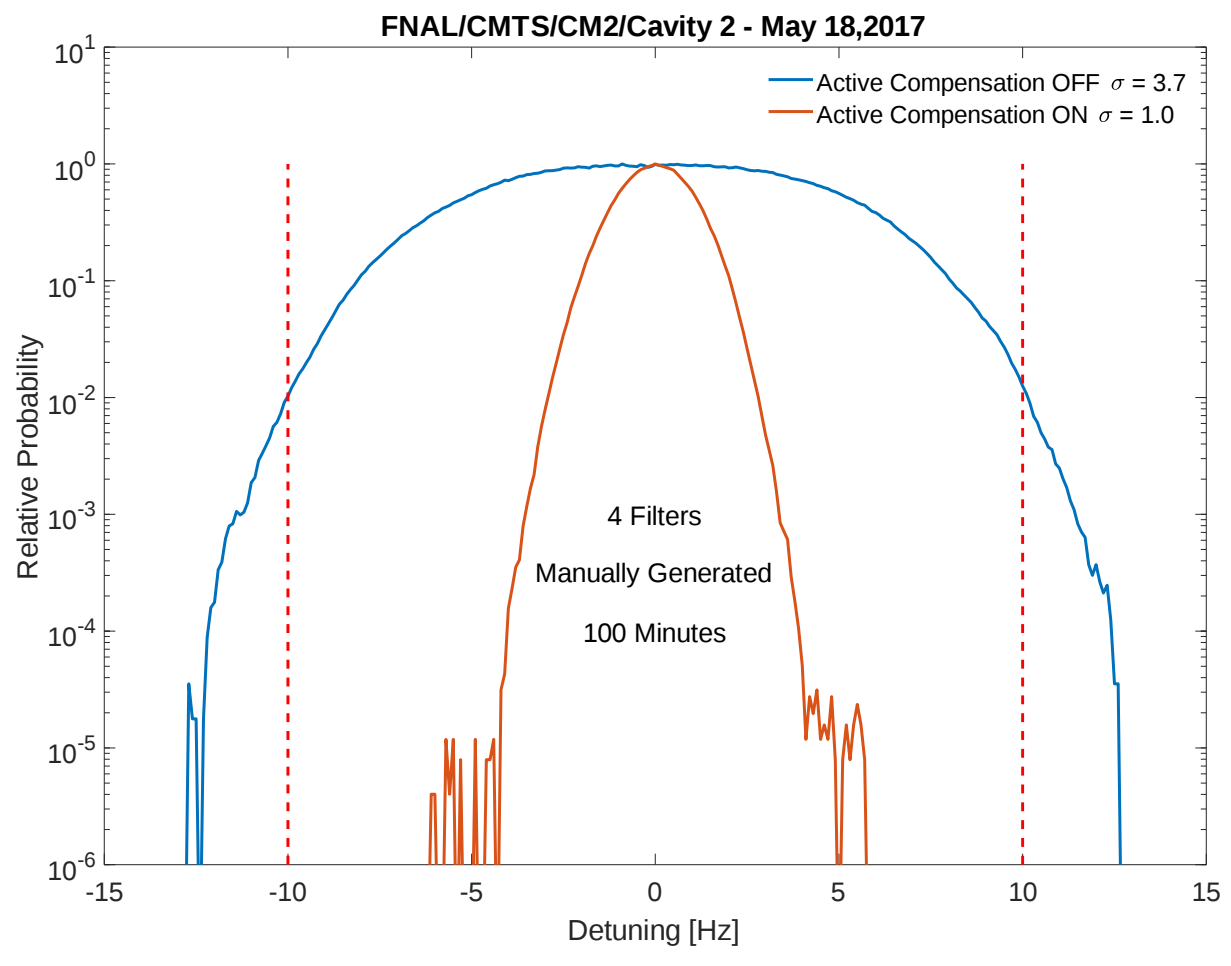




\section{Automatic Compensation in CM3/Cavity 1}

- Automated algorithm uses Least Squares to determine filter coefficients from

- measured detuning noise spectrum and

- piezo/detuning transfer function

- Single overall gain adjusted manually

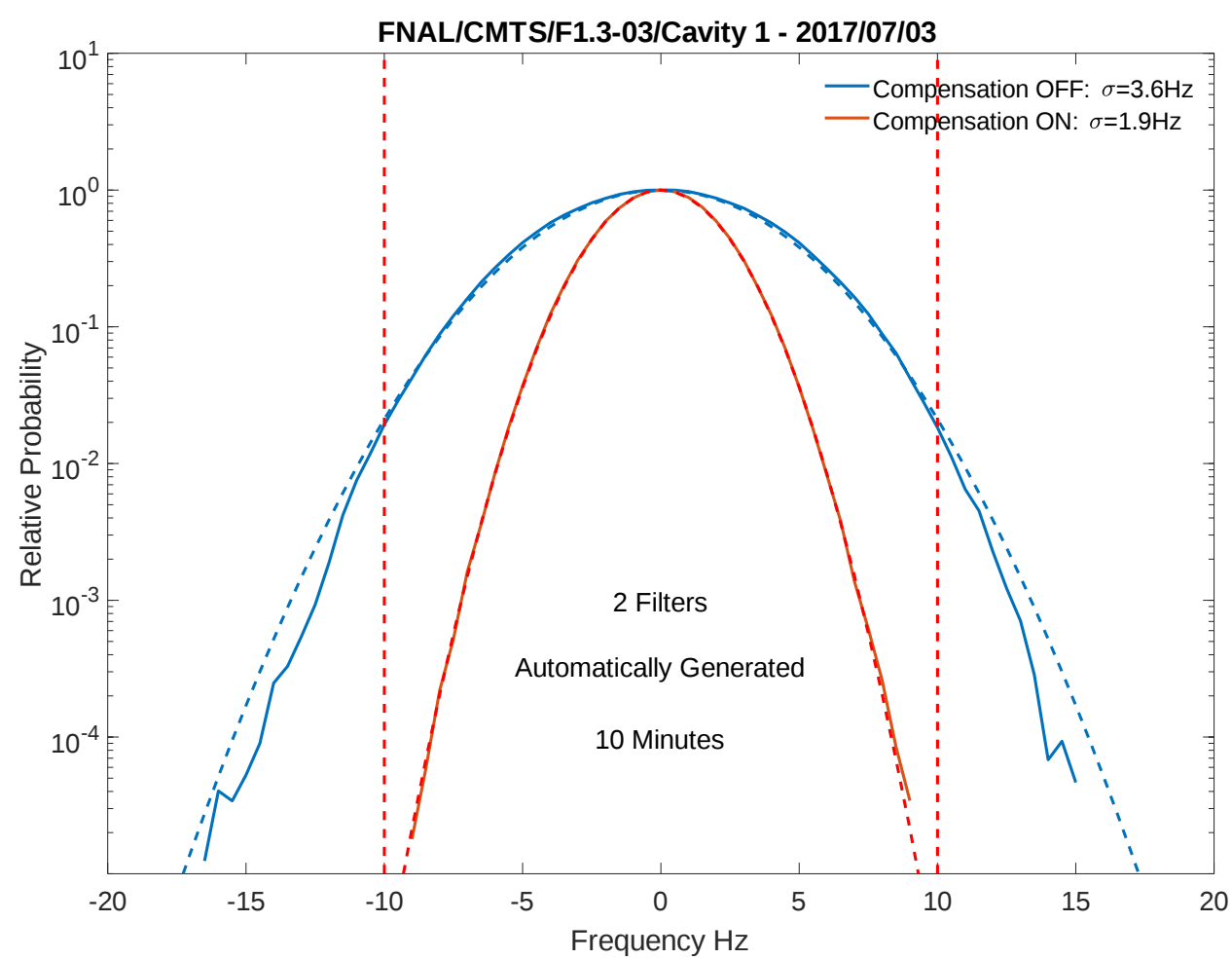


- Feedback: 1-2 Hz 3 dB low-pass cutoff PI controller, Kp 10-20, limited by tuner resolution and peak event stability

- Feedforward: Adaptive fourier-domain LMS

- Deconvolves piezo transfer function from the measured microphonics

- Phase shifter to compensate for loop phase

- Generated based on IFFT of detuning error signal FFT deconvolved form transfer function

$$
\begin{gathered}
y_{n}=\vec{w}_{n}^{T} \operatorname{IFFT}\left(\hat{\vec{e}}_{n} / H_{\text {piezo } \rightarrow \Delta f}\right) \\
e_{n}=H_{\text {ext } \rightarrow \Delta f} z_{n}-H_{\text {piezo } \rightarrow \Delta f} y_{n} \sin \left(\phi_{\text {shift }}\right) . \\
\vec{w}_{n+1}=\vec{w}_{n}-\mu \frac{e_{n} \vec{x}_{n}}{\beta+\vec{x}_{n}^{T} \vec{x}_{n}}
\end{gathered}
$$



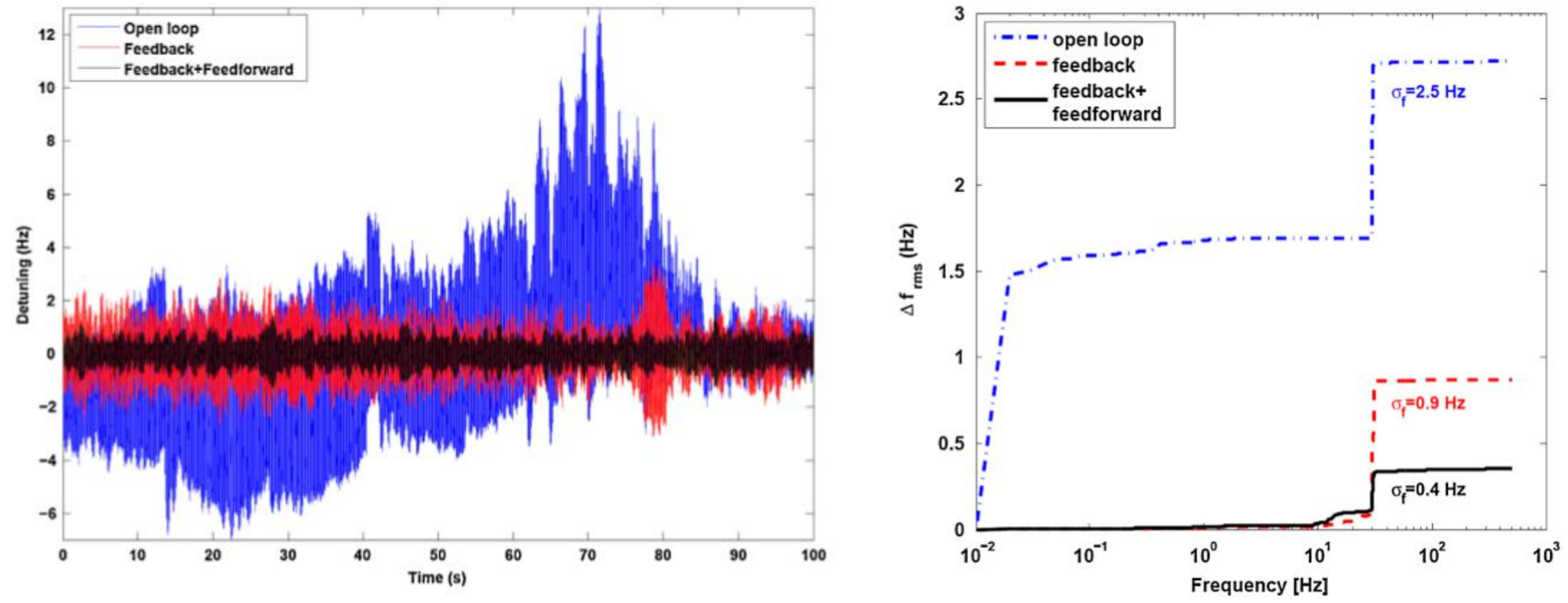

- LMS with Low-Frequency PI feedback 


\section{DESY}

- LMS with $\mathrm{N}$ notches per cavity

- Pipelined architecture

$$
H_{\mathrm{ANC}}(z)=\sum_{i=1}^{n_{\omega}} \mu_{i} A_{p, i}^{2}\left[\frac{z \cos \left(\omega_{i}-\phi_{p, i}\right)-\cos \phi_{p, i}}{z^{2}-2 z \cos \omega_{i}+1}\right]
$$

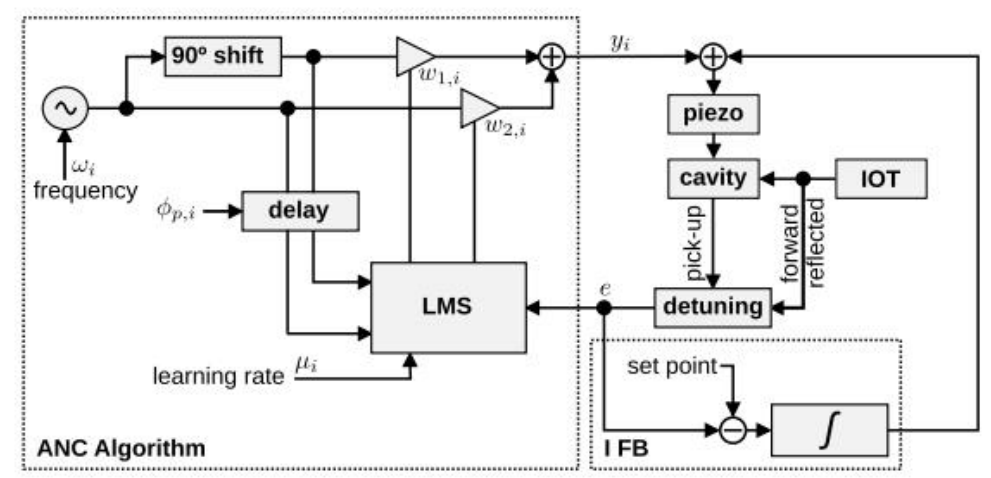

Fig. 6. Detuning compensation algorithm scheme.

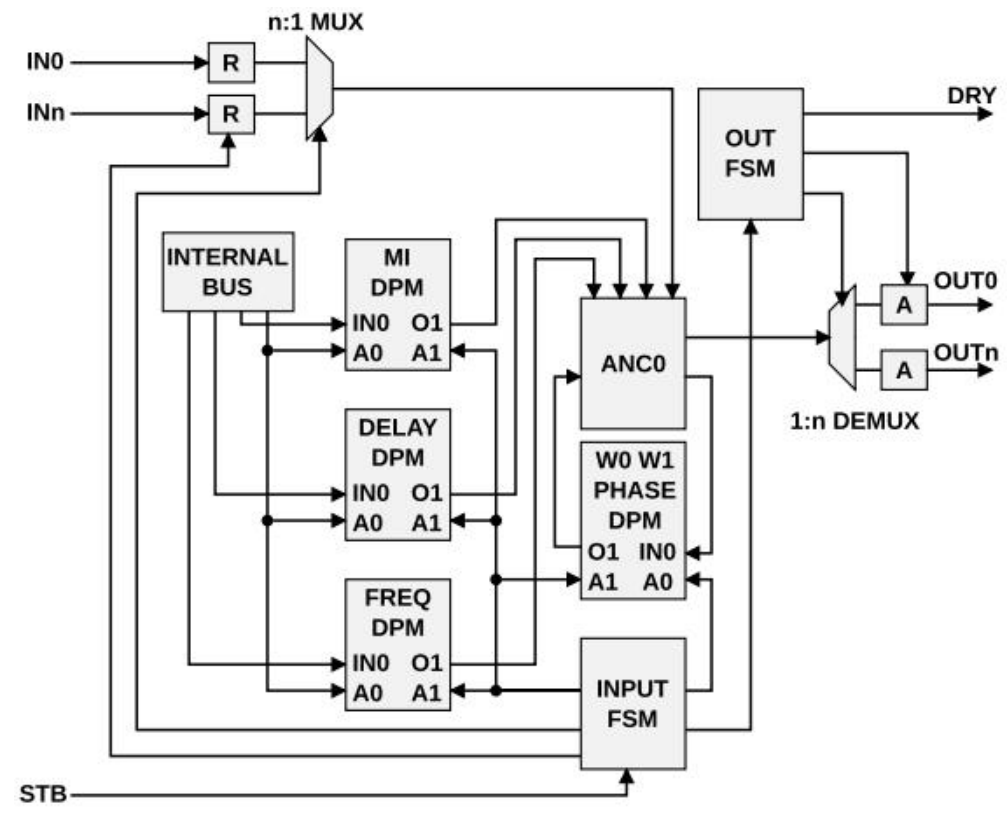




\section{DESY}
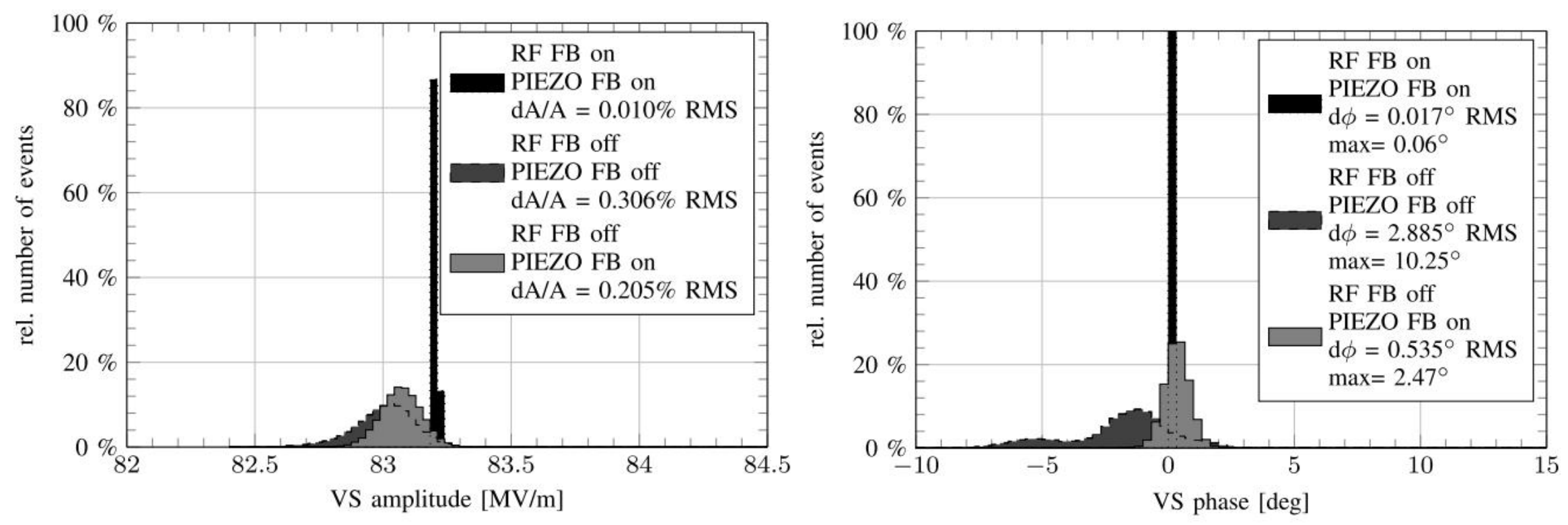


\section{APS}

- Narrowband (400th order) adaptive notch filter

- Excellent for removing discrete, narrowband sources

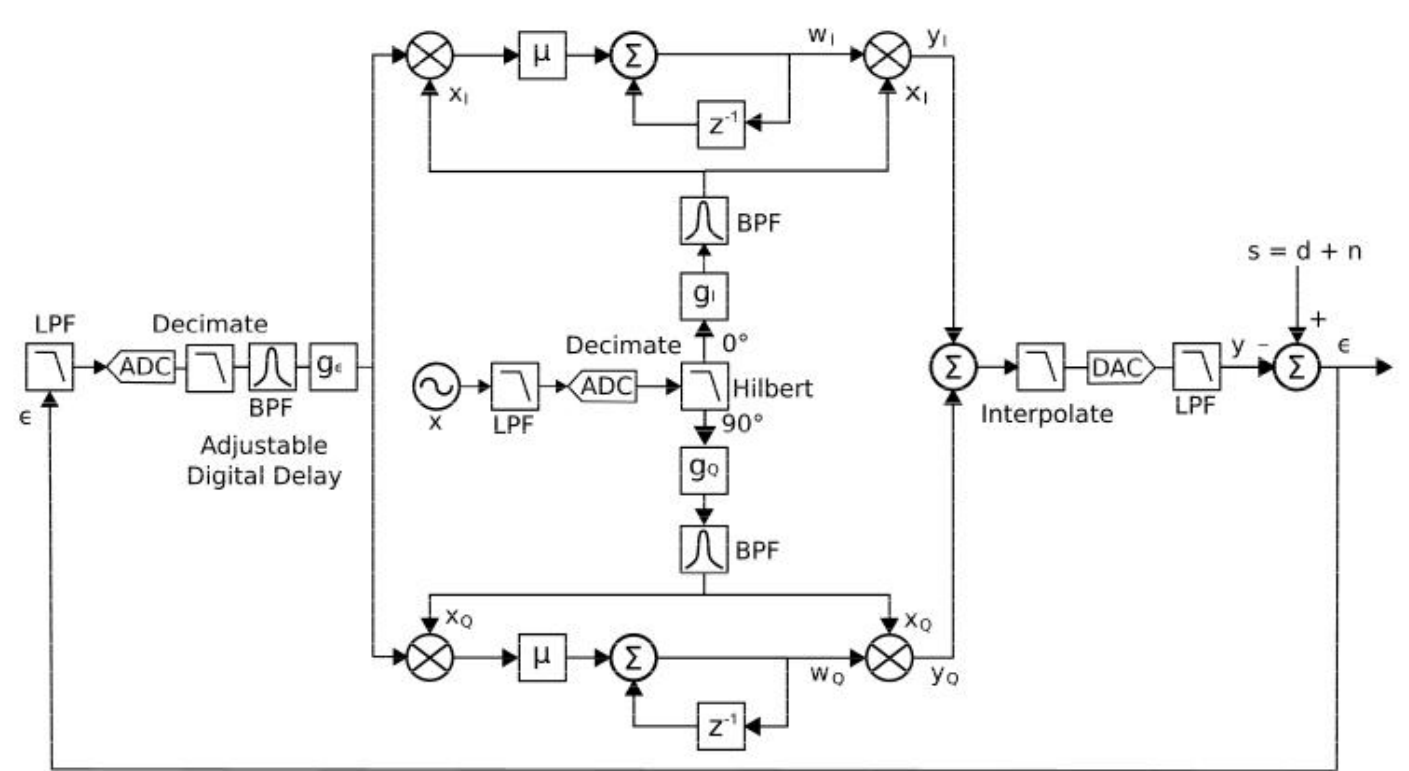




\section{APS}
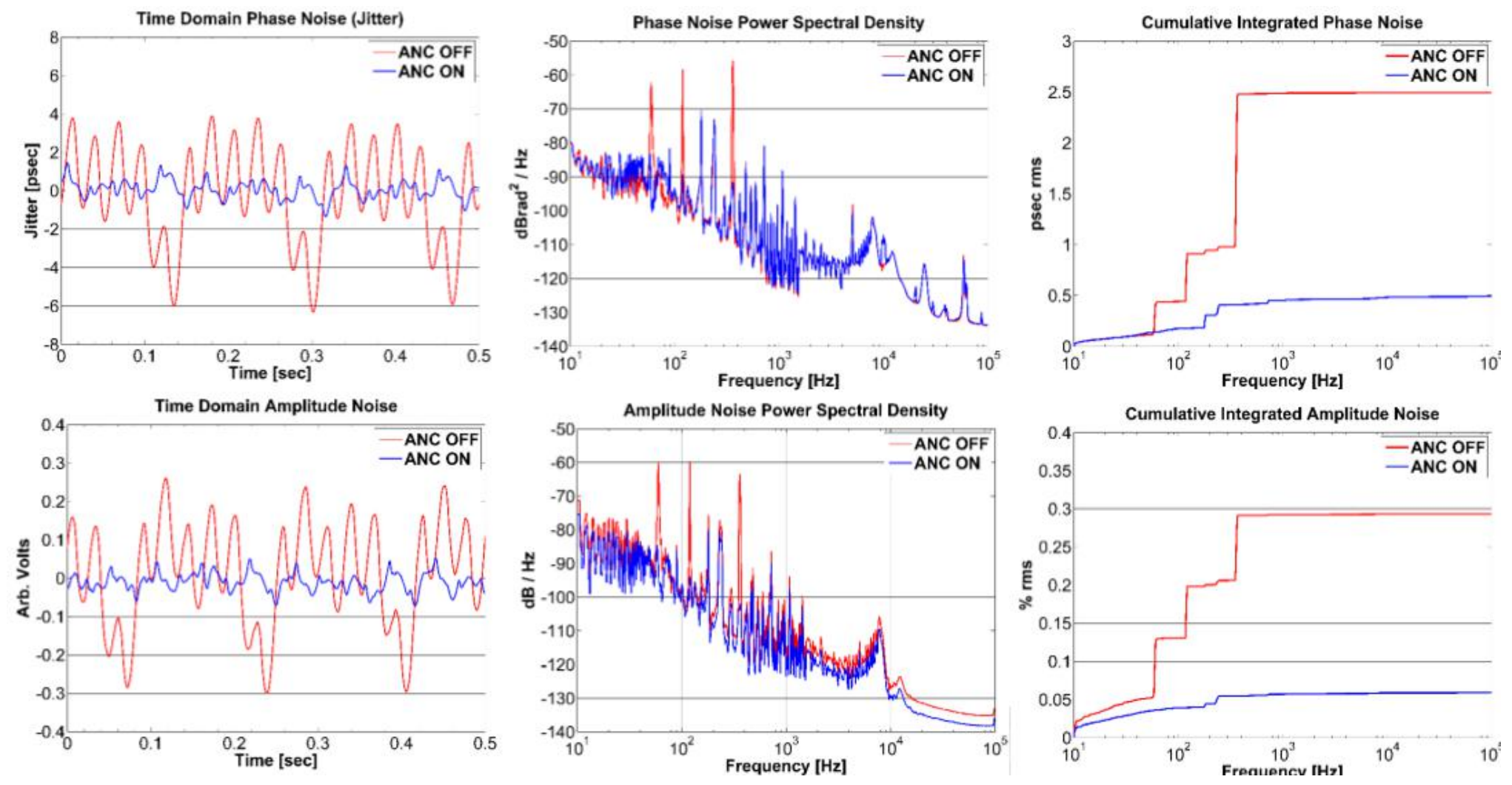


\section{Conclusion}

- Mitigation and control techniques requires an understanding of systematic issues

- Working in a black box is not a good idea

- Don't work on it alone and never take anything for granted

- Controller stability analysis is a necessity

- Thank You 


\section{Additional Slides}




\section{Audio Interpretations}

- Look at things in different ways 
- Contgrol bandwidth and theory

- DC Robinson Stability (neumann 2015)

- Warren microphonics and ARC. Download and use

- LCR circuit model used for feedback (neumann [11])

- Get audio recordings from emails and save. LCLS-II pCM

- get echo cancellation paper in correct location

- Model-based control

- LFD field**2 proportion for detuning vs integrator (square of cavity gradient. Makes sense, as we're balancing power)

- Standard feedback on the signal with notches helps. Is this good enough? That is the real question. Pull from wepty 036 
- Pirotte, O. Vibration monitoring of the rotating machines of the CERN cryogenic systems. 7th International Workshop on Cryogenics Operations, October 25-27, 2016 Fermi National Accelerator Laboratory, USA. https://indico.fnal.gov/event/11384/other-view ?view=standard

- Delayen, Jean. PONDEROMOTIVE INSTABILITIES, MICROPHONICS, and RF CONTROL. USPAS 2008.

- Ayvazyan, V., Simrock, S. Dynamic Lorentz Force Detuning Studies in TESLA Cavities. Proceedings of EPAC 2004, Lucerne, Switzerland.

http://citeseerx.ist.psu.edu/viewdoc/download ?doi=10.1.1.59.5092\&rep=rep $1 \&$ type $=$ pdf

- Schappert, W., et al. FIRST FERMILAB RESULTS OF SRF CAVITY LORENTZ FORCE DETUNING COMPENSATION USING A PIEZO TUNER. Proceedings of SRF2007, Peking Univ., Beijing, China. http://accelconf.web.cern.ch/AccelConf/srf2007/PAPERS/TUP57.pdf 
- Pirotte, O. Vibration monitoring of the rotating machines of the CERN cryogenic systems. 7th International Workshop on Cryogenics Operations, October 25-27, 2016 Fermi National Accelerator Laboratory, USA. https://indico.fnal.gov/event/1 1384/other-view ?view=standard

- Magnifotcham, F. and Snabre, P. Formation and rise of a bubble stream in a viscous liquid. Accepted: 11 May 1998. European Physical Journal B. pp 369-377.

- Luck, H. and Trepp, Ch. Thermoacoustic oscillations in cryogenics. Part 1: basic theory and experimental verification. Institute for Process and Cryogenic Engineering, ETH ZfJrich, ZfJrich, Switzerland. 16 March 1992 [3-part article series]

- Halford, D., et al. SPECTRAL DENSITY ANALYSIS: FREQUENCY DOMAIN SPECIFICATION AND MEASUREMENT OF SIGNAL STABILITY. National Bureau of Standards Boulder, Colorado 80302 USA

- Rutman, J. Characterization of Frequency Stability In Precision Frequency Sources. Proceedings fo the IEEE, Vol 79, No 6, June 1991.

- K R Atkins and C E Chase. The Velocity of First Sound in Liquid Helium. 1951 Proc. Phys. Soc. A 64826 
- Paleologu, Constantin \& Benesty, Jacob \& Ciochina, Silviu. (2010). A FAMILY OF VARIABLE STEP-SIZE NLMS ALGORITHMS FOR ECHO CANCELLATION. Revue Roumaine des Sciences Techniques - Serie Électrotechnique et Énergétique. 55.

- Kuo, S and Morgan, D.. Active Noise Control: A Tutorial Review. PROCEEDINGS OF THE IEEE, VOL. 87, NO. 6, JUNE 1999. pp 943-973.

- Hofler, A. and Delayen, J. SIMULATION STUDY OF ELECTRONIC DAMPING OF MICROPHONIC VIBRATIONS IN SUPERCONDUCTING CAVITIES. Proceedings of 2005 Particle Accelerator Conference, Knoxville, Tennessee. 


\section{References - Project Based}

- Holzbauer, J. 1.3 GHz Microphonics Measurement and Mitigations. LCLS-II DoE Review. June 13-15, 2017

- Holzbauer, J. F1.3-04 Microphonics Final Report. FNAL Microphonics Working Group. Tuesday, September 05, 2017.

- Neumann, A., et al. RF FEEDBACK AND DETUNING STUDIES FOR THE BESSY VARIABLE PULSE LENGTH STORAGE RING HIGHER HARMONIC SC CAVITIES. Proceedings of IPAC2015, Richmond, VA, USA.

- Powers, T. Control of Microphonics for Narrow Control Bandwidth Cavities. SRF Conference 2017.

- Powers, T. Microphonics and Energy Jitter. August 2017.

- Neumann, A., et al. Analysis and active compensation of microphonics in continuous wave narrow-bandwidth superconducting cavities. PHYSICAL REVIEW SPECIAL TOPICS -

ACCELERATORS AND BEAMS 13,082001 (2010)

- Jain, P. and Ben-Zvi, I. TEMPERATURE DEPENDENT MICROPHONICS IN THE BNL ELECTRON COOLER. Proceedings of IPAC2011, San Sebastián, Spain

- Kelly, M.P., et al. MICROPHONICS MEASUREMENTS IN SRF CAVITIES FOR RIA. Proceedings of the 2003 Particle Accelerator Conference 
- Berenec, T., et al. General Narrowband Noise Cancellation Development at the APS. First Microphonics Workshop. https://indico.fnal.gov/event/10555/

- Rybaniec, R., et al. FPGA-Based RF and Piezocontrollers for SRF Cavities in CW Mode. IEEE TRANSACTIONS ON NUCLEAR SCIENCE, VOL. 64, NO. 6, JUNE 2017 